\title{
Temperature Coefficients for Proving Rings
}

\author{
By Bruce L. Wilson, Douglas R. Tate, and George Borkowski
}

\begin{abstract}
Proving rings for calibrating testing machines are not compensated for change in elastic properties and dimensions with temperature. For this reason, temperature-correction factors must be used in computing ring loads from deflections obtained at temperatures that differ from the temperature of calibration. Temperature coefficients for 14 representative rings were computed from calibration results obtained at temperatures of $70^{\circ}$ and $100^{\circ} \mathrm{F}$. The temperature coefficient of one ring for the range $+70^{\circ}$ to $-93^{\circ} \mathrm{F}$ was determined from measurements of the natural frequencies at these temperatures. The temperature coefficient of a proving ring is shown to be equal to the temperature coefficient of Young's modulus of elasticity plus twice the coefficient of thermal expansion of the material of the ring.
\end{abstract}

\section{Introduction}

The proving ring is the most widely used elastic calibration device [1] ${ }^{1}$ for calibrating testing machines that apply forces to engineering materials and structures. About four-fifths of such devices submitted to the National Bureau of Standards for calibration during the past year were proving rings. The rings are not compensated for the change in elastic properties and dimensions with temperature, therefore, a knowledge of the temperature coefficient is required for use in computing ring loads from deflections obtained at temperatures that differ from the temperature during the calibration of the ring.

The tests described were undertaken (a) to determine experimentally the temperature coefficients of a number of representative proving rings for the usual range of room temperatures, (b) to determine the coefficient of a representative

1 Figures in brackets indicate the literature references given at the end of this paper.

\section{Contents}

Page

I. Introduction _...... 35

II. Description of proving ring _..._.

III. Theory of thermal effects _._._. 36

1. Relationship between temperature coefficient and deflection for proving rings ............... 36

2. Relationship between temperature coefficient of proving ring and temperature coefficient of Young's modulus of elasticity and coefficient of thermal expansion

3. Relationship between temperature coefficient and spring constant for proving rings. ....... 37

IV. Experimental procedure _.............. 38

1. Temperature range $70^{\circ}$ to $100^{\circ} \mathrm{F}_{\ldots} \ldots \ldots$

2. Temperature range $+70^{\circ}$ to $-93^{\circ} \mathrm{F} \ldots 38$

V. Results

1. Temperature range $70^{\circ}$ to $100^{\circ} \mathrm{F} \ldots \ldots 39$

2. Temperature range $+70^{\circ}$ to $-93^{\circ} \mathrm{F}_{\ldots} \ldots 40$

VI. Conclusions........................... 40

VII. References

88

98

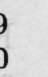
is 
ring at a temperature near $-100^{\circ} \mathrm{F}$, and (c) to determine whether the temperature coefficient may be calculated with sufficient accuracy from meas- ured values of the temperature coefficient of Young's modulus of elasticity and the coefficient of thermal expansion for the material of a ring.

\section{Description of Proving Ring}

The proving ring has been described in a previous paper [2]. Briefly, it is an elastic ring in which the deflection of the ring, when loaded along a diameter, is measured by means of a micrometer screw and a vibrating reed mounted diametrically in the ring. One of the rings used in the tests reported is shown in figure 1. This ring, which was used for the tests at $-93^{\circ} \mathrm{F}$, was made of steel having the following chemical composition: $\mathrm{C}, 0.50$ percent; $\mathrm{Cr}, 1.00$ percent; and $\mathrm{Ni}, 1.75$ percent. It was heat treated to show a Vickers number of about 475 (diamond indenter, load $=120$ $\mathrm{kg}$ ). It is believed that each of the proving rings tested had a total alloying content not exceeding 5 percent.

Proving rings are usually calibrated in deadweight machines [3], in which their deflections are determined for 10 uniformly spaced loads. The calibration factor, the ratio of the load to the deflection of the ring, is calculated, and the results are shown graphically as in figure 2. When a

\section{Theory of \\ 1. Relationship Between Temperature Coefficient and Deflection for Proving Rings}

The temperature coefficient, $k$, of a proving ring is defined by the equation

$$
k=\left(1 / F_{c}\right)(d F / d t),
$$

in which $F_{c}$ is the calibration factor for the ring at the standard temperature of calibration.

The calibration factor $F_{t}$ for any temperature, $\boldsymbol{t}$, becomes

$$
F_{t}=F_{c}\left[1+k\left(t-t_{c}\right)\right]
$$

where

$$
\begin{aligned}
& F_{t}=\text { calibration factor for a temperature of } \\
& \quad t \text { degrees } \\
& t_{c}=\text { standard temperature of calibration. }
\end{aligned}
$$

Equation 2 may be written in terms of deflections measured in dial divisions as

$$
d_{c}=d_{t}\left[1+k\left(t-t_{c}\right)\right] \text {, }
$$

ring is used to measure loads, the observed deflection is multiplied by the product of the calibration factor read from the calibration graph and a temperature correction factor.

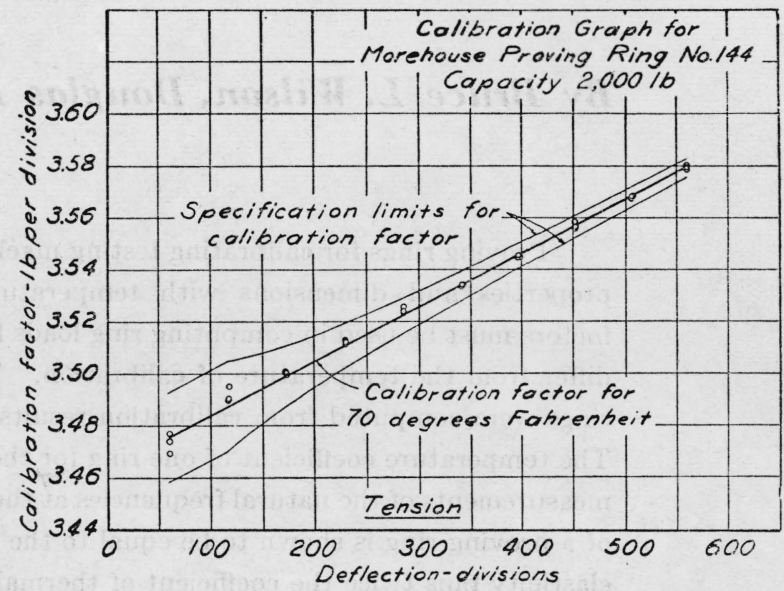

FIGURE 2.-Calibration graph for Morehouse proving ring No. 144 .

\section{Thermal Effects}

in which

$d_{c}=$ deflection of the ring at a temperature of $t_{c}$ degrees

$d_{t}=$ deflection of the ring at a temperature of $t$ degrees.

Solving equation 3 for the temperature coefficient

$$
k=\frac{d_{c}-d_{t}}{d_{t}\left(t-t_{c}\right)}
$$

By means of equation 4 the temperature coefficient for a ring may be computed from deflections for the same load obtained at different temperatures.

2. Relationship Between Temperature Coefficient of Proving Ring and Temperature Coefficient of Young's Modulus of Elasticity and Coefficient of Thermal Expansion

The deflection in the direction of the load of a closed circular ring of rectangular cross section 


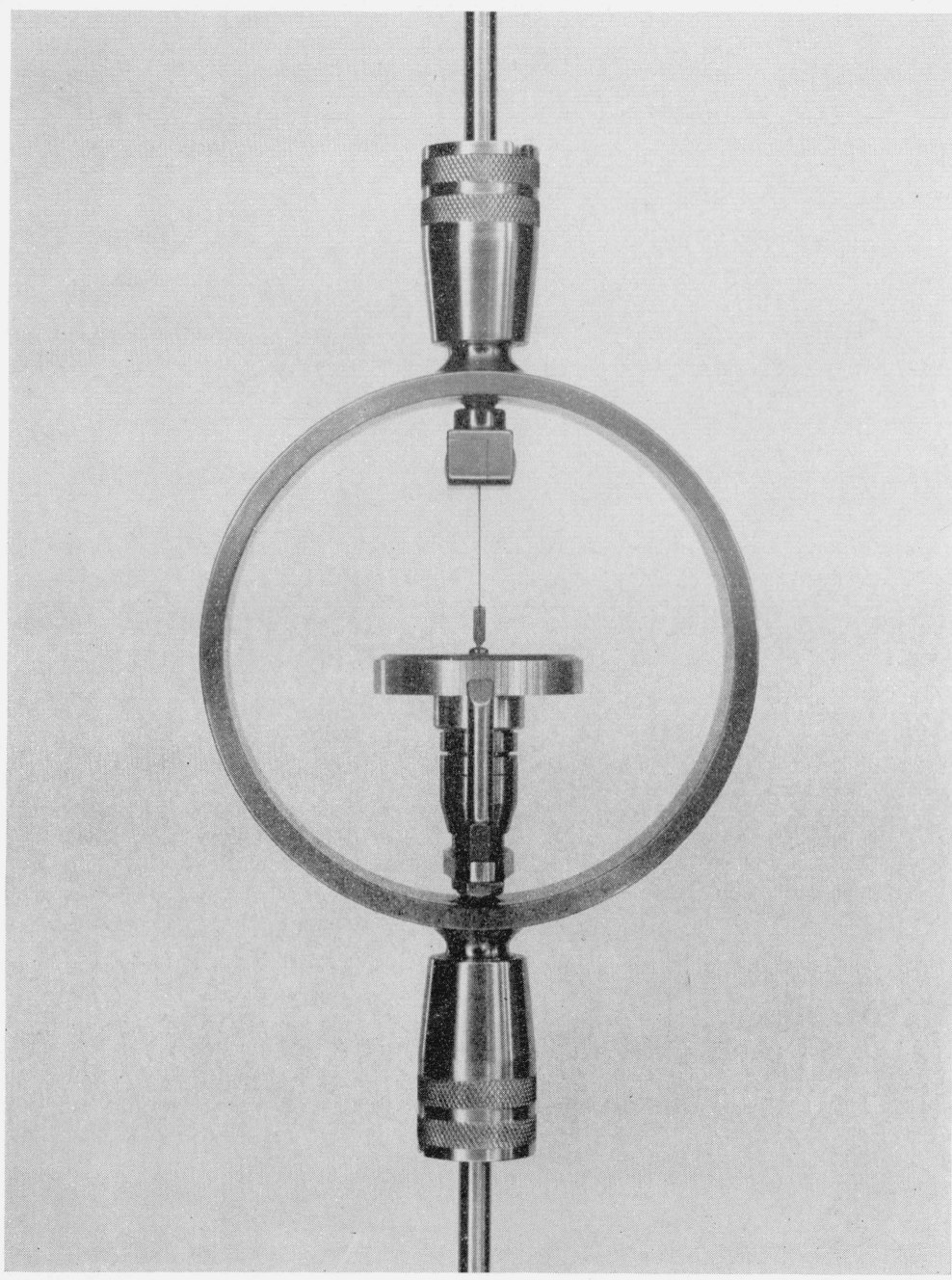

Figure 1.-Morehouse proving ring No. 144 , capacity $2,000 \mathrm{lb}$, with tension fittings attached to external bosses. 

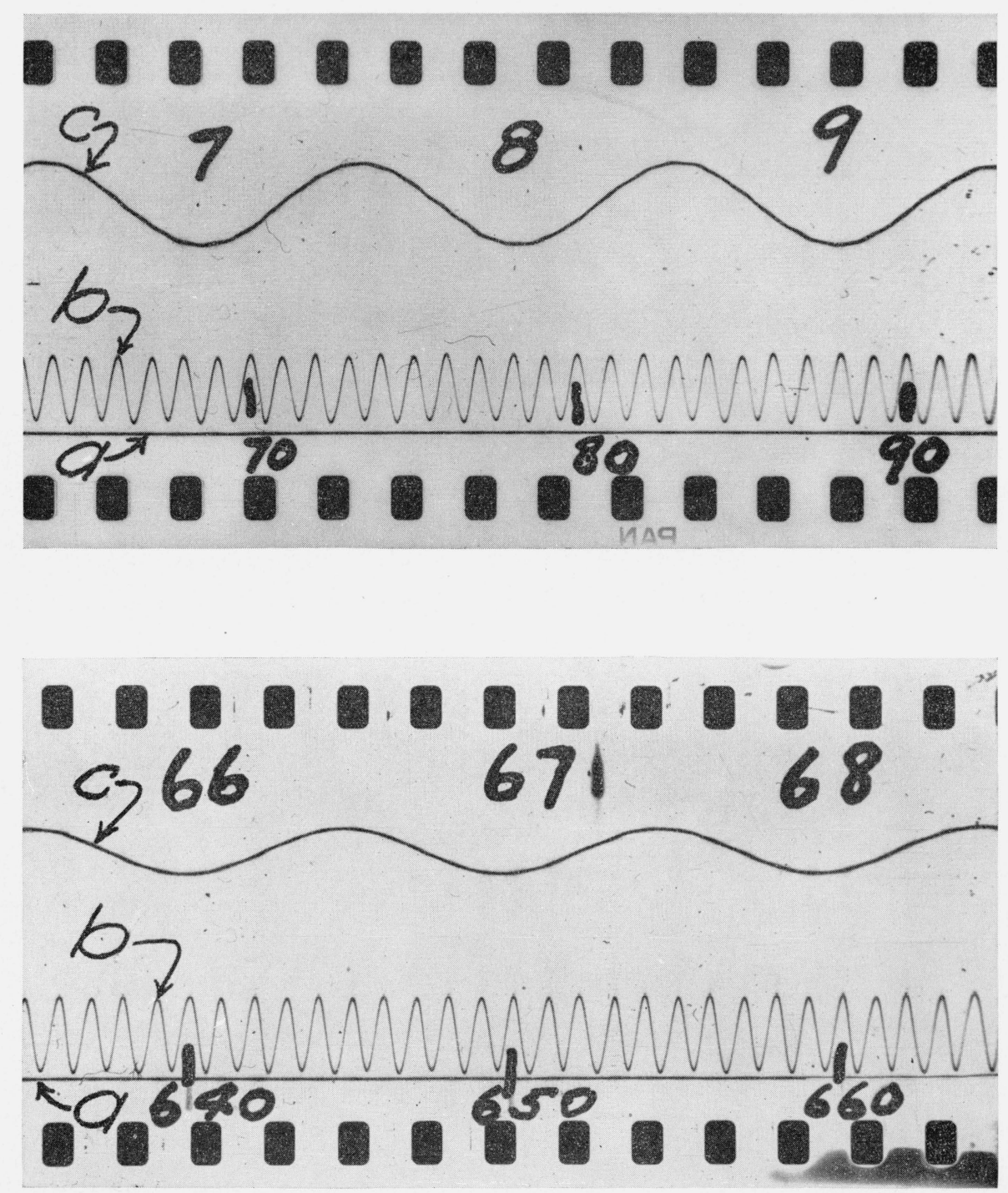

FIGURE 4.-Reproductions from film exposed in the autographic autocollimator; (a) reference line, (b) time scale, (c) ring vibration as indicated by Tuckerman strain gage. 
loaded at opposite ends of a diameter is given approximately by the expression eq 4 where

$$
d=A P r^{3} / E l h^{3},
$$

$d=$ deflection of the ring in the direction of the forces

$A=$ a numerical constant

$P=$ load on the ring

$r=$ initial radius of curvature of the neutral surface

$E=$ Youth's modulus of elasticity of the material of the ring

$l=$ width of the cross section of the ring

$h=$ thickness of the cross section of the ring.

The deflection of a proving ring is not exactly proportional to the load as indicated in equation 5. The calibration factor increases slightly with increasing tensile load as shown in figure 2 . Usually the calibration factor for 10-percent capacity load differs from the calibration factor for capacity load by less than 3 percent.

As the calibration factor of a proving ring is, by definition, the ratio of the load to the deflection of the ring measured in dial divisions, the effect of changing temperature on the micrometer screw should be included in the expression for the calibration factor. Usually the micrometer screw is made of steel and has about the same coefficient of thermal expansion as the ring. If the axial travel of the micrometer screw per unit dial division is denoted by $N$, the calibration factor $F$ may be written as

$$
F=(P N / d) .
$$

After combining equations 5 and 6 the result may be expressed as

$$
\begin{aligned}
& B=\text { a numerical quantity, constant for a } \\
& \text { given ring } \\
& E=\text { Young's modulus of elasticity, lb/in. }{ }^{2} \\
& L=\text { a quantity having the dimensions of } \\
& \text { length, in. }
\end{aligned}
$$$$
\text { in which }
$$

$$
F=B E L^{2},
$$

Differentiating equation 7 with respect to temperature and then dividing by equation 7 ,

$$
\frac{1}{F} \frac{d F}{d t}=\frac{1}{E} \frac{d E}{d t}+\frac{2}{L} \frac{d L}{d t} .
$$

Since the value of $F$ changes by less than 1 percent over the temperature range in which prov- ing rings are ordinarily used, it is permissible to write

$$
\frac{1}{F} \frac{d F}{d t}=\frac{1}{F_{c}} \frac{d F}{d t}=k,
$$

the temperature coefficient of the ring.

Since

$$
\frac{1}{E} \frac{d E}{d t}=e,
$$

the temperature coefficient of Young's modulus of elasticity

$$
\frac{1 d L}{L d t}=\alpha,
$$

the coefficient of linear thermal expansion. Equation 8 may be written

$$
k=e+2 \alpha .
$$

By means of equation 9 the temperature coefficient of a proving ring may be calculated from the temperature coefficient of Young's modulus of elasticity and the coefficient of thermal expansion.

\section{Relationship Between Temperature Coefficient and Spring Constant for Proving Rings}

The temperature coefficient of a proving ring may be computed from measurements at two temperatures of the natural frequency of the elastic system consisting of the ring and its load of dead

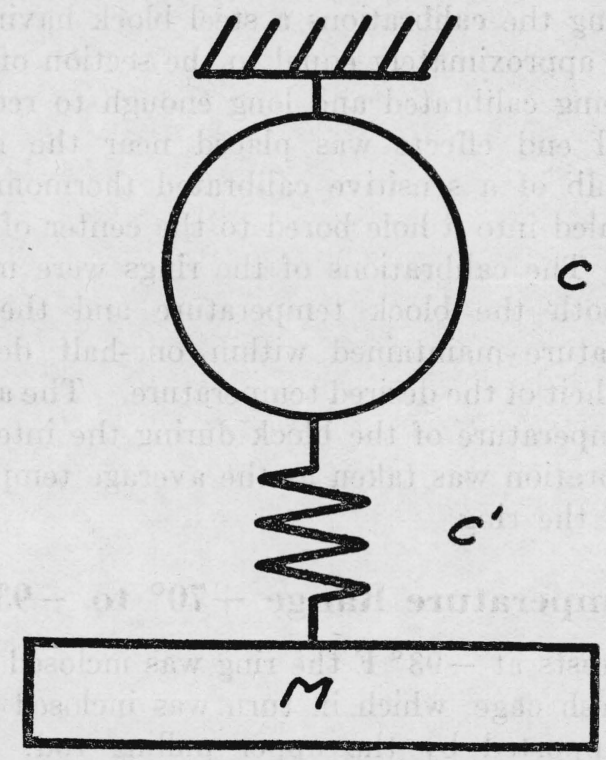

FIgURE 3.-Elastic system used in the vibration tests.

The load applied to the ring is represented by $M$, the spring constant of the ring by $c$, and the spring constant of the loading fixtures by $c^{\prime}$. 
weights shown in figure 3 . The natural frequency of the system may be written [5]

$$
f=\frac{1}{2 \pi} \sqrt{\frac{c c^{\prime}}{\left(c+c^{\prime}\right) m}}
$$

in which

$f=$ natural frequency of the system

$c=$ spring constant, load per unit deflection, for the proving ring

$c^{\prime}=$ spring constant for the loading fixtures

$m=$ mass suspended from the ring.

From equation 10 the spring constant for the ring at any temperature, $t$, is

$$
c_{t}=\frac{m c^{\prime}(2 \pi f)^{2}}{c^{\prime}-m(2 \pi f)^{2}}
$$

An expression for the temperature coefficient in terms of the spring constants of the ring may be derived from equation 4 , which gives the relationship between the temperature coefficient and the deflections of the ring. It may be shown that

in which

$$
k=\frac{c_{t}-c_{c}}{c_{c}\left(t-t_{c}\right)}+\alpha,
$$

$c_{t}=$ the spring constant of the ring for the temperature $t$ degrees

$c_{c}=$ the spring constant of the ring for the temperature $t_{c}$ degrees

$\alpha=$ the coefficient of linear thermal expansion.

The last term in equation 12 is due to the change in pitch of the micrometer screw with temperature. By means of equation 12 the temperature coefficient of a proving ring may be calculated from the spring constants of the ring for two different temperatures and the thermal coefficient of linear expansion of the material of the ring.

\section{Experimental Procedure}

\section{Temperature Range $70^{\circ}$ to $100^{\circ} \mathrm{F}$}

The tests were made in dead-weight testing machines [3], the loading frames of which are inclosed in a temperature controlled room. The air temperature of the room could be maintained near $70^{\circ}$ or $100^{\circ} \mathrm{F}$ and held constant to within one-half degree Fahrenheit.

During the calibrations a steel block having a section approximately equal to the section of the ring being calibrated and long enough to reduce thermal end effects was placed near the ring. The bulb of a sensitive calibrated thermometer was sealed into a hole bored to the center of the block. The calibrations of the rings were made with both the block temperature and the air temperature maintained within one-half degree Fahrenheit of the desired temperature. The average temperature of the block during the interval of calibration was taken as the average temperature of the ring.

\section{Temperature Range $+70^{\circ}$ to $-93^{\circ} \mathrm{F}$}

For tests at $-93^{\circ} \mathrm{F}$ the ring was inclosed in a wire-mesh cage, which in turn was inclosed in a box supported by the upper pulling rod. For the low-temperature tests the space between the wire-mesh cage and the box was packed with solid carbon dioxide. The box and cage were so designed that, although the ring was almost completely surrounded by solid carbon dioxide, sufficient clearance was provided for the ring to vibrate without damping effects produced by friction with the cage or the walls of the box. Vibration tests at $70^{\circ}$ were made with the box in place.

The temperature of the ring was measured by means of five calibrated chromel P-alumel thermocouples in contact with the surface of the ring. It is believed that the errors of the temperature measurements did not exceed 1 degree Fahrenheit. During the low-temperature tests, the temperature of the ring differed from point to point due to conduction of heat along the pulling rods, but in no case did the temperature measured at any point differ from the average temperature by more than 5 percent of the total temperature range.

Vibration of the ring was produced by a single impact of a small hammer swung from a constant height about a fixed axis. The hammer swung freely, struck a rubber pad, and was caught on the first rebound. Therefore, the initial amplitude of the ring vibration was very nearly constant.

The natural frequency of the vibration of the 2,000-lb-capacity ring loaded to about 60 -percentcapacity load was measured by means of a Tucker- 
man strain gage attached to projections on the pulling rods of the ring. The images from the gage, a reference mirror, and a vibrating mirror controlled by the standard 60-cycle-frequency signal from the Bureau's Radio Section were photographed in an autographic autocollimator. The film was moved continuously by a synchronous motor at a speed of approximately 10 inches per second. The length of film exposed during each run was sufficient to photograph at least 60 complete wavelengths of the ring vibration. Typical records are shown in figure 4.

The frequency was determined from measurements of the number of time waves corresponding to a fixed number of wavelengths of the ring vibration. By projection, the number of time wavelengths was determined to within 0.1 time wavelength. In no case, it is believed, did the error in the measurement of the frequency exceed 0.02 percent.

The effect of damping on the frequency was calculated from measurements of the amplitudes on each film. In no case was the calculated error due to damping greater than 0.001 percent.

Under ordinary conditions of use sufficient time elapses after the application or removal of load to a proving ring to permit almost complete temperature equalization before readings are observed, and the action may, therefore, be considered isothermal [6]. During the vibration tests the frequency was about 12 cycles per second, and the action was nearly adiabatic. As the difference between temperature coefficients for steel rings determined under isothermal and adiabatic conditions can be shown to be less than 1 percent [7], no correction was considered necessary.

The spring constant of the loading fixtures $\left(c^{\prime}\right.$, equation 10) was nearly independent of the temperature of the ring as the temperature of the air surrounding the rods and frame of the deadweight machine was constant. The constant $c^{\prime}$ was evaluated by substituting in equation 11 a value of $c_{t}$ derived from the calibration graph of the ring for $70^{\circ} \mathrm{F}$ and the measured natural frequency of the system for a ring temperature of $70^{\circ} \mathrm{F}$.

\section{Results}

\section{Temperature Range $70^{\circ}$ to $100^{\circ} \mathrm{F}$}

The temperature coefficients were determined for 14 proving rings for the range of temperatures from $70^{\circ}$ to $100^{\circ} \mathrm{F}$. In preliminary tests it was observed that the result obtained by computing the coefficient for the three highest of the 10 , uniformly spaced test loads applied to the ring, e. g., 80, 90, and 100 percent of capacity, did not differ significantly from the result computed for 10 uniformly spaced test loads. Therefore, the temperature coefficients were determined for the three highest test loads. The temperature coefficient, $k$ (equation 4) was computed for each ring by the method of least squares.

Typical average deflections for a 100,000-lbcapacity compression proving ring are as follows:

\begin{tabular}{|c|c|c|c|}
\hline & \multicolumn{3}{|c|}{ Applied load- } \\
\hline & $\begin{array}{c}80,000 \\
\mathrm{lb}\end{array}$ & $\begin{array}{l}90,000 \\
\mathrm{lb}\end{array}$ & $\begin{array}{c}100,000 \\
1 b\end{array}$ \\
\hline Deflection, for $101.6^{\circ} \mathrm{F}$, divisions & 484. 21 & 545. 33 & 606.67 \\
\hline Deflection, for $70.2^{\circ} \mathrm{F}$, divisions... & 482.07 & 542.82 & 603.82 \\
\hline Difference, divisions......... & 2. 14 & 2. 51 & 2.85 \\
\hline
\end{tabular}

TABLE 1.-Temperature coefficients for proving rings for the temperature range $70^{\circ}$ to $100^{\circ} \mathrm{F}$

\begin{tabular}{|c|c|c|}
\hline \multirow{2}{*}{ Capacity } & \multicolumn{2}{|c|}{ Temperature coefficient, $k$} \\
\hline & $\underset{\text { per }^{\circ} \mathrm{F}}{\text { Compression }}$ & $\underset{\mathrm{F}}{\mathrm{T}}{ }_{\mathrm{F}}$ \\
\hline \multicolumn{3}{|c|}{$\begin{array}{l}\text { MOREHOUSE MACHINE CO. } \\
\text { PROVING RINGS }\end{array}$} \\
\hline \multicolumn{3}{|l|}{ Pounds } \\
\hline 2,000 & -0.000144 & -0.000134 \\
\hline 10,000 & -.000148 & \\
\hline 10,000 & -.000143 & \\
\hline 10,000 & -.000152 & .... \\
\hline 10,000 & -.000146 & - \\
\hline 20,000 & -.000155 & -.000147 \\
\hline 50,000 & -.000155 & .... \\
\hline 100,000 & -.000160 & -.000149 \\
\hline 100,000 & -.000146 & \\
\hline 100,000 & -.000150 & \\
\hline 100,000 & -.000158 & \\
\hline \multicolumn{3}{|c|}{$\begin{array}{l}\text { TINIUS OLSEN TESTING MA- } \\
\text { CHINE CO. PROVING RINGS }\end{array}$} \\
\hline 2,000 & -0.000123 & \\
\hline 20,000 & -.000155 & \\
\hline 100,000 & -.000151 & \\
\hline
\end{tabular}

Average value of the temperature coefficient for proving rings, $k=-0.000148 /^{\circ} \mathrm{F}$ 
The temperature coefficient calculated from these data by the method of least squares is

$$
k=-0.000146 \text { per degree Fahrenheit }
$$

Temperature coefficients for the 14 proving rings are given in table 1.

The temperature coefficients for proving rings varied from -0.000123 to -0.000160 , the mean value being -0.000148 per degree Fahrenheit. This value corresponds to the value -0.000149 per degree Fahrenheit calculated by means of equation 9 from values for the coefficients of Young's modulus of elasticity and thermal expansion reported by Dadourian [8]. Keulegan and Houseman [9] reported results from which computed values were obtained ranging from -0.000132 to -0.000146 per degree Fahrenheit for steels of less than 5 percent total alloying content.

The temperature coefficient of one of the rings differed from the average value for all of the rings by 0.000025 per degree Fahrenheit. For this ring, correction by means of the average value for a temperature difference of $30^{\circ} \mathrm{F}$, a considerably greater temperature difference than is ordinarily encountered, would result in an error of 0.075 percent. This is less than the tolerance ( 0.1 percent) for proving rings [2].

\section{Temperature Range $+70^{\circ}$ to $-93^{\circ} \mathrm{F}$}

Low-temperature measurements were made on the proving ring shown in figure 1 . The calibra- tion graph for this ring for a temperature of $70^{\circ} \mathrm{F}$ is shown in figure 2.

The temperature-correction coefficient was calculated from measurements of the natural frequency of vibration recorded on six films. The following results were obtained.

\begin{tabular}{|c|c|c|c|}
\hline $\begin{array}{c}\text { Tempera- } \\
\text { ture }\end{array}$ & Frequency & $\begin{array}{c}\text { Spring } \\
\text { constant } \\
\text { of ring }\end{array}$ & $\begin{array}{c}\text { Temperature } \\
\text { coefficient } \\
\text { per }{ }^{\circ} \mathrm{F}\end{array}$ \\
\hline${ }^{\circ} \mathrm{F}$ & $c / s$ & lb/in. & \\
\hline 69.4 & 12.391 & 23,050 & -0.00023 \\
\hline-93.2 & 12.585 & 23,940 & - \\
\hline
\end{tabular}

The value -0.00023 obtained for the temperature range $+70^{\circ}$ to $-93^{\circ} \mathrm{F}$ differs considerably from the average value of -0.00015 obtained for the temperature range $70^{\circ}$ to $100^{\circ} \mathrm{F}$. Benton [10] also reported a considerable increase in the temperature coefficient of Young's modulus at low temperatures. The greatest source of error in the low-temperature tests was the nonuniformity of the temperatures of different portions of the ring. Nevertheless, it is believed that the value reported is not in error by more than 1 part in 23 .

As a check on the method used in the low-temperature tests, the temperature coefficient of a ring was measured by the same method over a temperature range of $70^{\circ}$ to $178^{\circ} \mathrm{F}$ by means of heaters mounted in the box used for the low-temperature tests. A value $k=-0.000153$ per degree Fahrenheit was obtained, which agrees with values obtained in the dead-weight machines.

\section{Conclusions}

The temperature coefficients of a group of 14 proving rings were measured for the temperature range $70^{\circ}$ to $100^{\circ} \mathrm{F}$ and found to average -0.00015 per degree Fahrenheit. This value is in agreement with values calculated from the results of other observers for this temperature range.

The work of Keulegan and Houseman [9] has indicated that the temperature coefficient of Young's modulus changes very slowly in the range of temperatures ordinarily encountered in the operation of testing machines. It is believed, therefore, that for rings made of steel having a total alloying content not exceeding 5 percent, the temperature coefficient will not vary more than 10 percent from $30^{\circ}$ to $120^{\circ} \mathrm{F}$. An error of 10 percent in the temperature coefficient will introduce less than 0.05-percent error in the calculated ring load for a temperature difference of $30^{\circ} \mathrm{F}$, a greater difference than is usually encountered.

The temperature coefficient of a proving ring was also measured for the temperature range $+70^{\circ}$ to $-93^{\circ} \mathrm{F}$ and found to be -0.00023 per degree Fahrenheit.

The temperature coefficients of rings made of steels having a total alloying content exceeding 5 percent may be expected to differ significantly from the values reported. 


\section{References}

[1] Am. Soc. Testing Materials Standards 1944, part I, Metals, p. 954 .

[2] B. L. Wilson, D. R. Tate, and G. Borkowskj, Proving rings for calibrating testing machines, Circular NBS C454 (1946).

[3] B. L. Wilson, D. R. Tate, and G. Borkowski, Deadweight machines of 111,000 - and 10,100-pound capacities, Circular NBS C446 (1943).

[4] S. Timoshenko, Strength of materials, part II, ch. 2 (D. Van Nostrand Co., Inc., New York, N. Y. 1930).
[5] Den Hartog, Mechanical vibrations, second edition, p. 41-49 (McGraw-Hill Book Co., Inc., New York, N. Y., 1940).

[6] L. B. Tuckerman, discussion, Proc. Am. Soc. Testing Materials, part II, 32, 594 (1932).

[7] J. H. Poynting and J. J. Thomson, A text-book of physics-heat, ninth edition, pp. 284-304 (Charles Griffin \& Co. Ltd., London, 1928).

[8] H. M. Dadourian, Phys. Rev. [II], XIII, 337 (1919).

[9] G. H. Keulegan and M. R. Houseman, BS J. Research 10, 289 (1933) RP531.

[10] J. R. Benton, Phys. Rev. 16, 17 (1903).

Washington, April 16, 1946. 